\title{
Non-uniformity of triaxial samples due to consolidation with radial drainage
}

\author{
J. H. ATKINSON, J. S. EVANS and E. W. L. HO (1985). Géotechnique 35, No. 3, 353-355
}

Mr H. L. Goh and Dr I. C. Pyrah, University of Sheffield

On the basis of a series of tests on kaolin the Authors have shown that non-uniform distributions of final moisture content can occur in triaxial specimens that are isotropically consolidated with radial drainage. Similar trends were predicted by Houlsby \& Nageswaran (1982) for specimens subjected to vertical deformation at constant axial stress and radial drainage. The Writers have recently completed a series of numerical analyses, and accompanying laboratory tests, to examine the behaviour of triaxial specimens subjected to different drainage and loading-deformation boundary conditions. In addition to the two loading conditions considered two other boundary conditions for consolidation with radial drainage have been examined. The four loading cases, which have been studied theoretically by Yoshikuni \& Nakanodo (1975), are shown in Fig. 1.

The numerical analyses of tests performed on $38 \mathrm{~mm}$ dia. specimens were carried out using CRISP, a finite element program developed at Cambridge University (Gunn \& Britto, 1986). The program includes several different soil models and adopts a fully coupled Biot approach to consolidation. The soil parameters are selected to represent the kaolin used in the experiments and the initial condition for the analysis is a uniform soil consolidated isotropically at a pressure of $280 \mathrm{kPa}$. The 'specimens' are then subjected to a further loading increment of $280 \mathrm{kPa}$ (i.e. $\Delta p^{\prime} / p_{0}{ }^{\prime}=1$ ) and the soil is allowed to consolidate under radial drainage conditions. For all four loading cases analyses using modified Cam

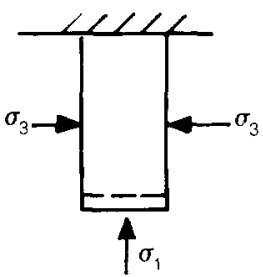

(a)

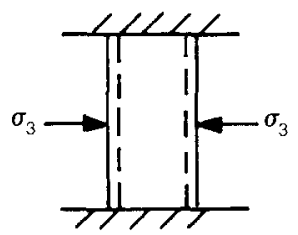

(b)

clay predicted non-uniformity of stress at the end of consolidation. The variations in mean effective stress, relative to the value at the centre of the specimen, are shown in Fig. 2; the pattern is similar to that predicted by the Authors deduced from the measured variations in moisture content. During consolidation a hardened shell is formed around the circumference of the specimen leaving a soft centre where the effective stresses never reach the values applied at the boundaries. The variations across the specimen of the three stress components at the end of consolidation are shown in Fig. 3 for a specimen subjected to isotropic loading.

The numerical predictions are, at present, being compared with the results of the laboratory tests carried out at Sheffield to assess the performance of numerical models in predicting real soil behaviour. As reported previously (Pyrah, 1979) although the tests and the analysis are relatively simple to carry out the problem exhibits true three-dimensional behaviour, as is shown by the observed variations in moisture content and predicted mean effective stress across the specimens.

As discussed by the Authors the nonuniformities introduced by the use of side drains in routine triaxial tests may significantly affect the subsequent measured strength and stress-strain behaviour. The results also illustrate the importance of adopting a fully coupled approach in the analysis of geotechnical problems. Many problems are simply analysed as 'undrained' (giving the stresses, pore pressures and displacements at the end of construction) and/or as completely 'drained' (giving the long-term stresses and displacements); if rates of consolidation are

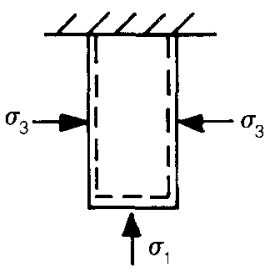

(c)

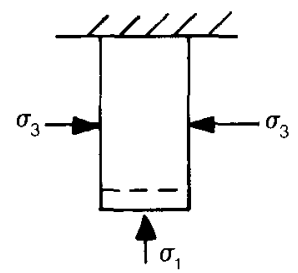

(d)

Fig. 1. Loading-deformation boundary conditions for triaxial consolidation tests with radial drainage: (a) case 1, $K_{0}$ consolidation (axial stress constant); (b) case 2 , no vertical strain consolidation; (c) case 3 , isotropic consolidation; (d) case $4, K_{0}$ consolidation (radial stress constant) 


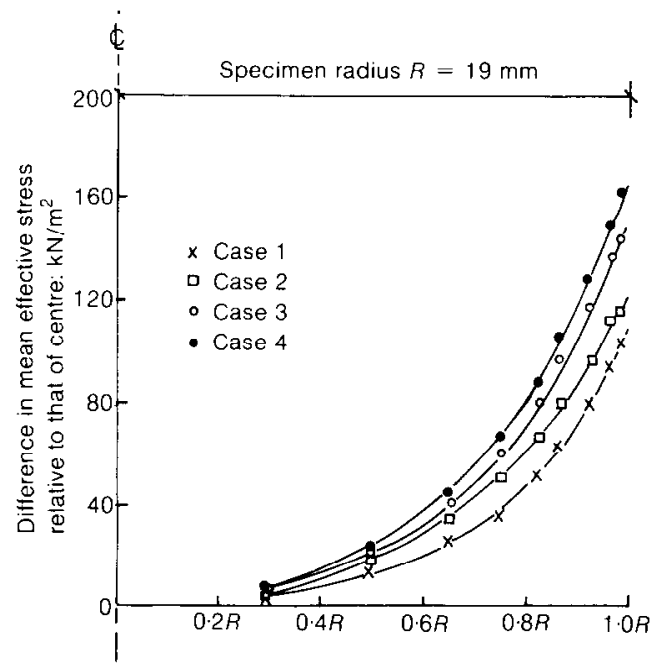

Fig. 2. Variation in mean effective stress across triaxial specimens

required these may be estimated using diffusion theory. Although this is simpler than a fully coupled approach, it cannot predict effects such as those discussed in the Technical Note, nor can these effects be predicted by elastic analysis for it is the non-elastic soil behaviour which creates the non-uniformities. Although further research is required to investigate which type of problem requires a full consolidation analysis it is probable that for situations wherc yicld is likely to occur a fully coupled Biot approach should be adopted, even if it is only the long-term stresses

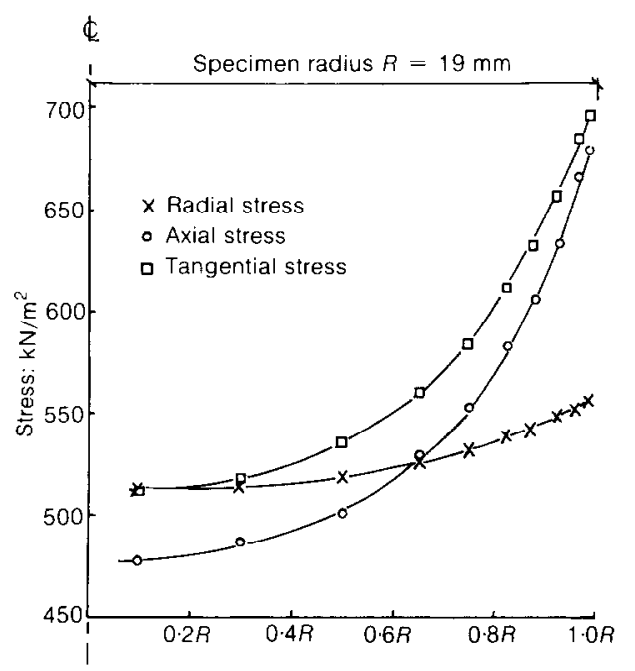

Fig. 3. Variation in stress across a triaxial specimen consolidated isotropically with radial drainage $\left(p_{0}{ }^{\prime}=280\right.$ $\mathrm{kPa}, \Delta p^{\prime}=280 \mathrm{kPa}$ ) and/or displacements which are of interest. Where only elastic strains are expected the long-term condition can probably be predicted with sufficient accuracy by carrying out a single drained analysis using the effective stress deformation parameters.

\section{REFERENCES}

Gunn, M. J. \& Britto, A. M. (1986). Finite elements in critical state soil mechanics. To he published.

Houlsby, G. T. \& Nageswaren, S. (1982). A study of consolidation with radial drainage. Critical State Soil Mechanics Workshop, Cambridge University Engineering Department.

Pyrah, I. C. (1979). Discussion on session 1. Proc. 7th Eur. Conf. Soil Mech. Fdn Engng, Brighton 4, 44-47.

Yoshikuni, H. \& Nakanodo, H. (1975). Consolidation of a clay cylinder with external radial drainage. Soils Fdns 15, No. 1, 17-27.

\section{Authors' reply}

The Writers' results confirm the Authors' findings that radial drainage can give rise to significant non-uniformities during consolidation of soil samples in routine tests.

Numerical work has also been conducted at The City University using the CRISP package (Woods, 1986). This work investigated the influence of both loading rate and boundary conditions for drainage and displacement on the resultant radial non-uniformities. It should be noted that in a triaxial sample with rigid top and bottom platens uniform stresses from the cell pressure are applied to the top of the top platen and, owing to non-uniform consolidation and stiffening in the sample, the stresses between the sample and the top platen will vary across the radius. The finite element analyses reported by Woods (1986) included a rigid top platen in the mesh, but it is not clear whether this was done by the Writers. Fig. 4 shows the radial variation in water content against loading rate for samples compressed isotropically $(\Delta p=200 \mathrm{kPa})$ with allround drainage. A modified Cam clay constitutive model was used with $\kappa=0.05, \lambda=0.25$, $M=1 \cdot 0, \Gamma=3 \cdot 4, v^{\prime}=0 \cdot 3, k_{x}=k_{v}=1 \times 10^{-9}$ $\mathrm{m} / \mathrm{s}, \gamma_{\mathrm{w}}=10 \mathrm{kN} / \mathrm{m}^{3}$ and $p_{0}{ }^{\prime}=200 \mathrm{kPa}$. This figure may be compared with Fig. 2 in the Authors' original Technical Note which is for soil with approximately the same parameters, except that $\lambda=0.20$ and $p_{0}{ }^{\prime}=25 \mathrm{kPa}$. The same features are reproduced, with the exception that, at lower loading rates, an apparent residual variation in water content of $0.3 \%$ was found in the laboratory experiments.

The Authors fully agree with the Writers that the fully coupled Biot (1941) analysis should be used for situations in which yield is likely to occur. Such analyses arc rcadily implemented in a 


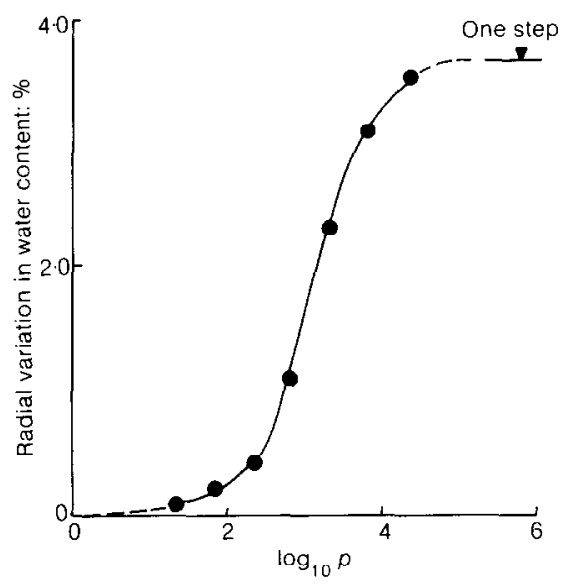

Fig. 4. Radial variation in water content against the logarithm of the loading rate for isotropically compressed samples with all-round drainage (after Woods (1986)) finite element solution scheme and are able to predict important effects that are completely missed by the uncoupled approach (such as the Mandel-Cryer effect (Mandel, 1953; Cryer, 1963). It should be emphasized that further research is necessary to establish the consequences of nonuniform water content on the subsequent behaviour of soil samples and to relate these to permissible rates of drained loading.

\section{REFERENCES}

Biot, M. A. (1941). General theory of three dimensional consolidation. J. Appl. Phys. 12, 155-164.

Cryer, C. W. (1963). A comparison of the threedimensional theories of Biot and Terzaghi. Q.J. Mech. Appl. Math. 16, 401-412.

Mandel, J. (1953). Consolidation des sols (étude mathématique). Géotechnique 3, 287-299.

Woods, R. I. (1986). Finite element analysis of coupled loading and consolidation. Proc. 2nd Int. Symp. Numerical Models in Geomechanics, Ghent. 